\title{
Removal of heavy metal chromium from tannery effluent using ultrafiltration membrane
}

\author{
P. Angelin Vinodhini and P. N. Sudha*
}

\begin{abstract}
The present study was aimed to fabricate a novel ultrafiltration membrane using cellulose acetate, nanochitosan, and polyethylene glycol of ratio 1:2:2 by phase inversion method. Analytical techniques such as Fourier transform infrared spectroscopy (FTIR), X-ray diffractometer (XRD), and scanning electron microscopy (SEM) have been employed to characterize the prepared membrane. FTIR and XRD results revealed the formation of blended membrane with increased amorphous nature. SEM studies exhibited the rough surface with numerous pores. The prepared membrane was also characterized for its ultrafiltration performance by membrane compaction, pure water flux, water content, and porosity. The results showed that the membrane obtained a pure water flux of $25.32 \mathrm{l} / \mathrm{m}^{2} \mathrm{~h}$. The water content was found to be $24 \%$ and a high porosity of $83 \%$ was obtained which showed the membrane's high hydrophilicity and more porous nature. The main focus of the present study was toxic hexavalent chromium removal from tannery effluent using the prepared hydrophilic membrane, which causes various adverse effects. The effect of pH of the solution (viz., pH 5, 7, and 9), membrane thickness ( 0.1 and $0.2 \mathrm{~mm}$ ), and the applied pressure (50 and $100 \mathrm{kPa}$ ) were studied which are the key factors in determining the efficiency of the prepared membrane in remediation of tannery effluent. The results showed high percentage removal of chromium at pH 7 using $0.2 \mathrm{~mm}$ thickness at $100 \mathrm{kPa}$. The physicochemical parameters of the tannery effluent were also found to be reduced.
\end{abstract}

Keywords: Cellulose acetate, Nanochitosan, Polyethylene glycol, Ultrafiltration membrane, Remediation of tannery effluent

\section{Background}

The one and only substance that is found on earth's crust for the survival of living things is water which regulates the earth's temperature as well as the temperature of the human body. The most valued water is now get polluted by the anthropogenic activities by the emission of domestic or urban sewage, agricultural waste, pollutants, and industrial effluents. There are numerous data and statistics which claim that the earth's water resources are being depleted, polluted, and rendered unpotable at an alarming rate (Malik et al. 2014). Thus, the whole world is under stress for the want of pure water. The main source of water pollution is industrial effluents which consist of acids, alkalis, toxic heavy metals, oil, grease, dyes, pesticides, and even radioactive materials.

\footnotetext{
* Correspondence: drparsu8@gmail.com

P.G. and Research Department of Chemistry, D.K.M College for Women, Vellore, Tamil Nadu, India
}

Heavy metals which are the natural constituents of the earth crust are persistent environmental contaminants because they cannot be degraded or destroyed (Duruibe et al. 2007). Heavy metals such as mercury, lead, cadmium, copper, and chromium are toxic even in small amounts (Pang et al. 2015). The health hazards associated with exposure to chromium are dependent on its oxidation state. The hexavalent form, $\mathrm{Cr}(\mathrm{VI})$, is toxic and has adverse effects on the skin like ulcerations, dermatitis, and allergic skin reactions. It is also proved to be carcinogenic (Barbooti 2015). The chromium removal techniques available are precipitation, adsorption, and solvent extraction (Moosa et al. 2015) among which membrane techniques have been proven to be one of the respective methods. It is simple and economical for the removal of heavy metal ions from aqueous solution.

A wide range of polymeric materials have been used to prepare various membrane types. The choices of polymer 
taken for the current study are the biopolymer chitosan in its nanosize, a porogen polyethylene glycol, and membrane matrix material cellulose acetate. Each polymer has their unique properties constituting for the performance of the membrane prepared. The second most abundantly available chitin is deacetylated to get chitosan (Sudha 2010) which is further converted into its nanoform by suitable crosslinking agents. Owing to its invaluable applications, chitosan (CS) has become very vital in various fields like pharmaceutical (Kato et al. 2003; Kumar et al. 2004), biomedical (Suh and Matthew 2000; Tucci and Rocotti 2003; $\mathrm{Ng}$ and Swami 2005), water treatment (Northcott et al. 2005; Crini 2005), cosmetics (Rinoudo 2006; Sun et al. 2006), agriculture (Boonlertniruni et al. 2008; El Hadrami et al. 2010), and food industry (Ham-Pichavant et al. 2005; De Lima et al. 2010). The properties of chitosan are found to be more enhanced when used in its nanoscale. Thus, the ever increasing field of nanotechnology has also been implemented in the present study.

Cellulose acetate (CA), the most important cellulose ester was one of the first membrane polymer used for aqueous-based separations and used both as reverse osmosis and UF membrane material (Kuttowy and Sourirajan 1975). Its convincing properties such as good toughness, high biocompatibility, good desalting, high flux, and relatively low cost (Idris and Yet 2006) makes it versatile for use as membrane matrix. Another important additive for membrane is the pore forming agent which is very essential for the formation of pores in the membrane. The synthetic polyether polyethylene glycol (PEG) was employed as porogen which is inexpensive, non-toxic, and also soluble in many organic solvents like toluene, ethanol, acetone, and chlorinated hydrocarbons. However, it is insoluble in ethers, aliphatic hydrocarbons, fats, and mineral oil (Rowe et al. 2003). So far, there is no literature found for using nanochitosan in membrane technology which emphasizes the novelty of the present work.

Thus, the main objective of the present work is to prepare a novel ultrafiltration membrane of nanochitosan, cellulose acetate, and polyethylene glycol using popular phase inversion process, to characterize for its formation and suitability using Fourier transform infrared spectroscopy (FTIR), X-ray diffractometer (XRD), scanning electron microscopy (SEM), membrane compaction, pure water flux, water content, and porosity and to find the efficiency of the prepared membrane for the removal of chromium from tannery effluent and the analysis of the results to achieve the most favorable conditions.

\section{Methods}

\section{Materials}

Commercial grade cellulose acetate and sodium lauryl sulfate (SLS) were obtained from ChenChems, India.
Chitosan was purchased from India Sea Foods, Cochin, Kerala, which is $92 \%$ deacetylated. Polyethylene glycol and acetic acid were procured from Sisco Research Laboratories Pvt. Ltd., Mumbai, India. $N, N^{\prime}$-dimethylformamide was procured from Thermo Fisher Scientific India Pvt. Ltd., Mumbai. Sodium tripolyphosphate (TPP) was procured from Finar Chemicals Limited, Ahmedabad, India. Deionized and distilled water was employed for the preparation of nanochitosan and gelation bath.

\section{Preparation of nanochitosan}

Nanochitosan was prepared by sol-gel method using TPP. Ten grams of chitosan was dissolved in $2000 \mathrm{ml}$ of $2 \%(v / v)$ acetic acid. The above solution was stirred well for $45 \mathrm{~min}$. Then, $100 \mathrm{ml}$ of $0.75 \mathrm{mg} / \mathrm{ml}$ TPP was dropped into the beaker. A milky emulsion was obtained. The nanochitosan was washed several times in deionized water. This solution was then allowed to settle for $24 \mathrm{~h}$. The supernatant solution was then decanted (Sivakami et al. 2013). Particle size of the prepared nanochitosan was investigated by using a dynamic light scattering (DLS) device (zeta plus from Brookhaven), and the average particle size of nanochitosan was found to be $100 \mathrm{~nm}$.

\section{Fabrication of membranes Solution blending of polymers}

Membrane was prepared using CA, NCS, and PEG in 1:2:2 ratio with a polar solvent dimethylformamide (DMF) under constant mechanical stirring for $1 \mathrm{~h}$ at room temperature. The homogeneous polymer solution obtained was allowed to stand for $10 \mathrm{~min}$ in an airtight condition to get rid of air bubbles.

\section{Casting of membranes}

The membrane was prepared by phase inversion process (Witte et al. 1996; Loeb and Sourirajan 1963; Arthanareeswaran et al. 2007; Nath 2008; Velu et al. 2011) which is a well-known technique to prepare asymmetric membranes. The deaerated polymeric solution was casted on a glass plate, and the thickness of the membrane was maintained about $0.2 \mathrm{~mm}$ approximately. After allowing the solvent to evaporate, the glass plate was immersed in the gelation bath for final precipitation.

Prior to membrane casting, 21 gelation bath consisting of $2.5 \%(v / v)$ DMF and $0.2 \mathrm{wt} . \%$ SLS in distilled water (non-solvent) was prepared and cooled to $15 \pm 2{ }^{\circ} \mathrm{C}$ (Arthanareeswaran et al. 2004). After gelation process, the membrane was removed from it and washed thoroughly with demineralized water and subsequently stored in $0.1 \%$ formalin solution to prevent microbial growth. 


\section{Membrane characterization FTIR}

A thermo nicolet AVATAR 330 IR spectrophotometer was used to record the IR spectra within the range of $4000-400 \mathrm{~cm}^{-1}$. The IR spectra were recorded in a solid state using a $\mathrm{KBr}$ pellet method.

\section{$X R D$}

The molecular packing of the blend membranes were analyzed with X-ray powder diffractometer (XRD-SHIMADZU $\mathrm{XD}$-D1) using a Ni-filtered $\mathrm{Cu} \mathrm{K} \alpha \mathrm{X}$-ray radiation source. Percentage of crystallinity $\mathrm{X}_{\mathrm{C}} \%$ was measured as a ratio of crystalline area to the total area of the peaks using the formula given by Nara and Komiya (1983).

\section{SEM}

The surface and cross-sectional morphology of the prepared blend membranes were viewed and photographed using scanning electron microscopy. For the analysis, the blend membranes were cut into pieces of various sizes and wiped with filter paper. The membranes were coated with a thin gold-palladium layer by a sputter coater unit (VG-Microtech, UCK field, UK), and the cross section topography was analyzed with a Cambridge stereoscan 440 scanning electron microscope (SEM, Leica, Cambridge, UK) operated at an acceleration voltage of $20 \mathrm{kV}$.

\section{Ultrafiltration characterization Membrane compaction}

The prepared membranes were thoroughly washed and cut into desired size and loaded in the UF test cell of $38.5 \mathrm{~cm}^{2}$ area and initially pressurized with distilled water at $240 \mathrm{kPa}$. The water flux was measured at every $10 \mathrm{~min}$. The flux generally declines initially and attained steady state after 90 min of compaction. The prepressurized membranes were used in subsequent ultrafiltration experiments at $100 \mathrm{kPa}$ (Kuttowy and Sourirajan 1975).

\section{Pure water flux}

Membranes after compaction were subjected to pure water flux estimation at a transmembrane pressure of $100 \mathrm{kPa}$. The flux was measured under steady state flow. The pure water flux was determined (Osada and Nakagawa 1992) using the expression,

$$
J_{\mathrm{w}}=\frac{Q}{\Delta t \times A}
$$

where $J_{\mathrm{w}}$ is the pure water flux $\left(\mathrm{l} \mathrm{m}^{-2} \mathrm{~h}^{-1}\right), Q$ is the amount of permeates collected (l), $\Delta t$ is the sampling time (h), and $A$ is the membrane area $\left(\mathrm{m}^{2}\right)$.

\section{Water content}

Water content of the membranes were obtained after soaking membranes in water for $24 \mathrm{~h}$ and the membranes were weighed followed by mopping it with blotting paper. These wet membranes were placed in vacuum drier at $75{ }^{\circ} \mathrm{C}$ for $48 \mathrm{~h}$ and cooled it to room temperature in a dessicator, and the dry weights of the membranes were determined. The percent water content was calculated (Tamura et al. 1981) by using the following equation:

$\%$ water content $=\frac{\text { wet sample weight }- \text { dry sample weight }}{\text { wet sample weight }} \times 100$

\section{Porosity}

The overall porosity $(\varepsilon)$ was determined by gravimetric method, as defined in the following equation (Li et al. 2009):

$$
\varepsilon=\frac{w_{1}-w_{2}}{A \times l \times d_{\mathrm{w}}}
$$

where $w_{1}$ is the weight of the wet membrane, $w_{2}$ is the weight of the dry membrane, $A$ is the membrane effective area $\left(\mathrm{m}^{2}\right), d_{\mathrm{w}}$ is the water density $\left(0.998 \mathrm{~g} / \mathrm{cm}^{3}\right)$, and $l$ is the membrane thickness $(\mathrm{m})$.

\section{Collection of tannery effluent from Ranipet, Vellore District, Tamilnadu}

The effluent sample for the current study was collected from the final discharge point wherein effluent from all the stages of processing were treated and released together from a leather tanning unit in Ranipet, Vellore district, Tamilnadu, India, to the water stream. Polythene containers of $5 \mathrm{l}$ capacity was used for the collection of effluent samples and immediately transported to the laboratory with due care and stored at $4{ }^{\circ} \mathrm{C}$ in refrigerator until further analysis.

The color of the tannery effluent was observed visually and recorded, and the odor was detected by smelling. $\mathrm{pH}$ was measured using Elico $\mathrm{pH}$ meter on the site. Other physicochemical parameters such as $\mathrm{pH}$, electrical conductivity (EC), dissolved oxygen (DO), biochemical oxygen demand (BOD), chemical oxygen demand (COD), total dissolved solids (TDS), total solids (TS), total hardness $(\mathrm{TH})$, salinity, turbidity, and sodium were analyzed in the laboratory following standard methods (APHA 1993; Trivedy and Goel 1986).

\section{Remediation of tannery effluent using prepared blend membrane by studying the effect of $\mathrm{pH}$ of the solution, membrane thickness, and applied pressure}

The effluent that has already undergone primary and secondary treatment process in industry itself and that which is let out to the water streams was collected and 
subjected to subsequent ultrafiltration process. The UF cell was fixed with the prepared membrane and was filled with the tannery effluent solution, and filtration was started. The permeate was collected periodically in the stoppered bottles, and the physicochemical factors were analyzed after each period of remediation as per the methods of APHA (1993) and Trivedy and Goel (1986). The heavy metal chromium was analyzed using Atomic absorption spectrometer (Varian 4AA Atomic Absorption Spectrometer).

The percentage chromium rejection was calculated from the concentration of chromium in the feed and permeates using the equation given below.

$$
\% \text { Cr rejection }=\left[1-\left(C_{\mathrm{p}} / C_{\mathrm{f}}\right)\right] \times 100
$$

where $C_{\mathrm{p}}$ is the concentration of chromium in permeate and $C_{\mathrm{f}}$ is the concentration of chromium in feed.

The extent of remediation of the effluents was investigated by changing the $\mathrm{pH}$ of the solution, membrane thickness, and applied pressure. The physicochemical parameters of the effluent before and after treatment were measured as mean of three individual observations. The physical and chemical characteristics of the raw effluent were analyzed and given in Table 1 along with the accepted limit given by ISI standards for disposal of industrial wastewater of inland surface water.

Table 1 Physicochemical analysis of tannery effluent

\begin{tabular}{lll}
\hline Parameters & Raw effluent & Accepted limits $^{a}$ \\
\hline $\begin{array}{l}\text { Physical parameters } \\
\text { Color }\end{array}$ & Blackish color & Colorless \\
Odor & Disagreeable smell & Odorless \\
pH & 7.43 & $6.5-8.5$ \\
Chemical parameters & \\
$\begin{array}{l}\text { Electrical conductivity (EC) } \\
\text { (mS/cm) }\end{array}$ & 27.3 & 0.288 \\
$\begin{array}{l}\text { Dissolved oxygen (DO) mg/l } \\
\text { Biochemical oxygen demand }\end{array}$ & 0.2 & $4-6$ \\
(BOD) mg/l & 2556 & 30 \\
$\begin{array}{l}\text { Chemical oxygen demand } \\
\text { (COD) mg/l }\end{array}$ & 6419 & 250 \\
Total dissolved solids (TDS) & 15,900 & 2100 \\
mg/l & & 2200 \\
Total solids (TS) mg/l & 31,740 & 300 \\
Total hardness (TH) mg/l & 923 & Not mentioned \\
Salinity (mg/l) & 16,200 & 10 \\
Turbidity (NTU) & 453 & $1000-1500$ \\
Sodium (mg/l) & 5000 & 2.0 \\
Chromium (Cr) (mg/l) & 1055 & \\
\hline
\end{tabular}

Values expressed as mean of six individual values

${ }^{a}$ ISI standards for disposal of industrial wastewater of inland surface water

\section{Effect of $\mathrm{pH}$}

$\mathrm{pH}$ is the most important of all the factors affecting the removal of heavy metals. $\mathrm{pH}$ adjustment is extremely important as well since it can be used as a means to selectively separate heavy metals from multicomponent mixtures and the removal rate to separate heavy metals differs when $\mathrm{pH}$ is carefully adjusted (Zeng et al. 2009). The effect of $\mathrm{pH}$ on the filtration of tannery effluent by the membrane was carried out at room temperature and at three different $\mathrm{pH}$ values.

\section{Effect of membrane thickness}

Thickness is a key parameter in membrane processes since it influences both the membrane selectivity and the membrane resistance against flux (Abdelrasoul et al. 2015). It also plays an important role in the amount of conductive heat loss though the membrane. The filtration study was conducted using two different membrane thicknesses, viz., 0.1 and $0.2 \mathrm{~mm}$.

\section{Effect of applied pressure}

The transmembrane pressure is the driving force for the pressure-driven membrane process (Gökşen 2005). Applied pressure is considered as one of the most critical aspects in the membrane performance and operation. The UF experiment was carried out at two different pressures namely 50 and $100 \mathrm{kPa}$.

\section{Results and discussion \\ Membrane characterization \\ FTIR}

IR spectroscopy is an excellent method and has been extensively used for the qualitative analysis in which specific absorption peaks can be identified for particular groups (Qu et al. 2010). The interactions between the functional groups in a polymer blend can be obtained directly and gross structural details can be investigated. The chemical nature of a substance including chemical bonds, molecular orientations, molecular energy levels, and molecular interactions (Gorey and Escobar 2011) can be assessed using this technique. Thus, the prepared blend has been analyzed using FTIR, and the possible interactions that had taken place were studied.

The FTIR spectral details of the prepared NCS are shown in Fig. 1. A prominent broad peak at $3385.92 \mathrm{~cm}^{-1}$ indicates the presence of $\mathrm{O}-\mathrm{H}$ and $\mathrm{N}-\mathrm{H}$ stretching vibration (Vimal et al. 2013). Peak at $1324.83 \mathrm{~cm}^{-1}$ is assigned to $\mathrm{P}=\mathrm{O}$ stretching vibration whereas at $1038.87 \mathrm{~cm}^{-1}$ is assigned to $\mathrm{P}-\mathrm{O}$ stretching vibration. The $\mathrm{N}-\mathrm{H}$ bending vibration corresponds to the peak at $1510.05 \mathrm{~cm}^{-1}$ which was proved by Mohammadpour Dounighi et al. (2010) who obtained peak at $1540 \mathrm{~cm}^{-1}$ in CS/TPP nanoparticles. The deformation vibrations of $\mathrm{C}-\mathrm{H}$ and $\mathrm{O}-\mathrm{H}$ groups were observed at 1431.02 and $1376.80 \mathrm{~cm}^{-1}$. A peak for 


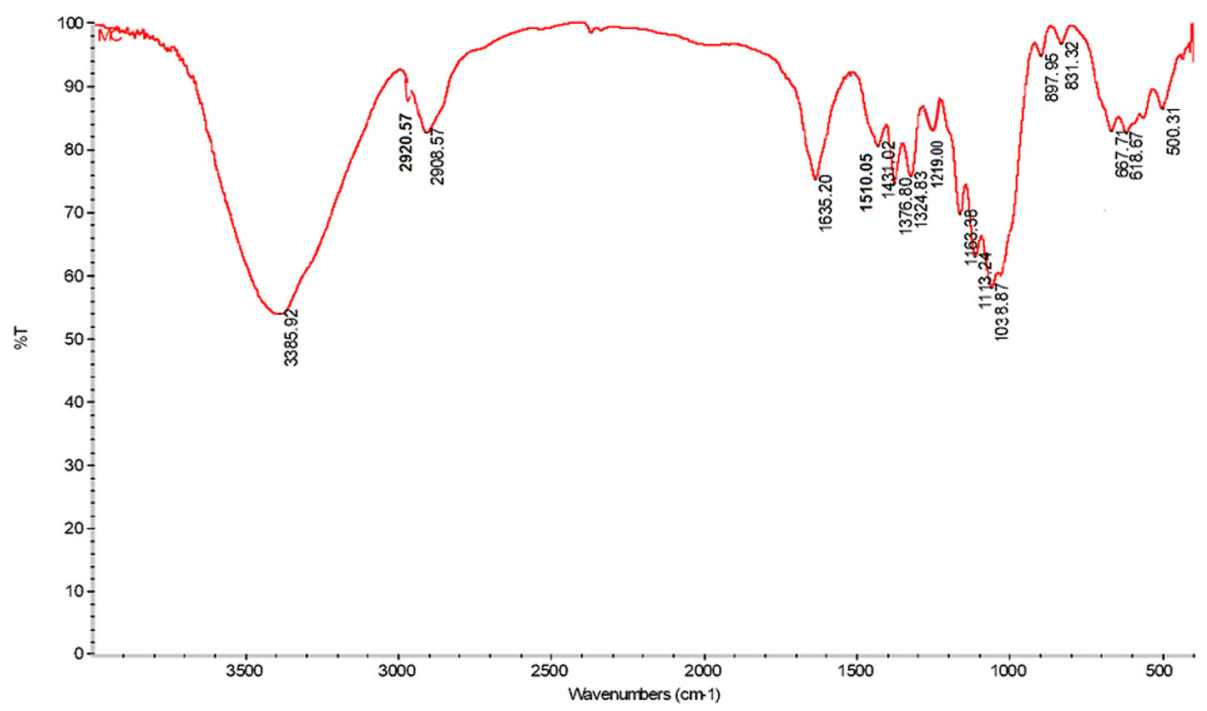

Fig. 1 FTIR spectrum of nanochitosan

$\mathrm{C}=\mathrm{O}$ stretching vibration is observed at $1635.20 \mathrm{~cm}^{-1}$. Peaks at $1219.00,1163.38$, and $1113.24 \mathrm{~cm}^{-1}$ were due to $\mathrm{C}-\mathrm{N}$ stretching, $\mathrm{C}-\mathrm{O}$ stretching, and $\mathrm{C}-\mathrm{O}-\mathrm{C}$ ether linkages, respectively.

The FTIR spectral details of CA/NCS/PEG (1:2:2) blend membrane are given in Fig. 2. The $\mathrm{O}-\mathrm{H}$ and $\mathrm{N}-\mathrm{H}$ stretching vibration of the membrane is observed at $3389.80 \mathrm{~cm}^{-1}$ which is wider. The $\mathrm{O}-\mathrm{H}$ stretching is attributed to the enhanced intermolecular hydrogen bonding formed between the polymers (Yu et al. 1999). The peaks at $2948.54 \mathrm{~cm}^{-1}$ and $1642.36 \mathrm{~cm}^{-1}$ were due to the asymmetric $\mathrm{C}-\mathrm{H}$ stretching and $\mathrm{C}=\mathrm{O}$ stretching vibration, respectively. The peak at $1495.20 \mathrm{~cm}^{-1}$ was assigned to the deformation vibration of $\mathrm{N}-\mathrm{H}$. A peak for $\mathrm{P}=\mathrm{O}$ stretching vibration was found at $1284.14 \mathrm{~cm}^{-1}$ and for $\mathrm{P}-\mathrm{O}$ stretching vibration at $1014.99 \mathrm{~cm}^{-1}$ which showed a shift from $1038.87 \mathrm{~cm}^{-1}$ characteristic of pure NCS (Vijayalakshmi et al. 2014). C-N stretching vibration and $\mathrm{C}-\mathrm{O}-\mathrm{C}$ ether linkage were observed at 1220.51 and $1056.94 \mathrm{~cm}^{-1}$, respectively.

There is a shift in the $\mathrm{OH}$ and $\mathrm{NH}$ frequencies for the prepared membrane from NCS, i.e., the peak obtained at $3385.92 \mathrm{~cm}^{-1}$ has been shifted to $3389.80 \mathrm{~cm}^{-1}$. The $\mathrm{C}=\mathrm{O}$ peak at $1635.20 \mathrm{~cm}^{-1}$ for NCS has been found to be shifted to $1642.36 \mathrm{~cm}^{-1}$. Peak at $1324.83 \mathrm{~cm}^{-1}$ for $\mathrm{P}=\mathrm{O}$ was observed to have a shift in the IR spectrum to $1284.14 \mathrm{~cm}^{-1}$. This shows that there is strong intermolecular hydrogen bonding taking place which leads to

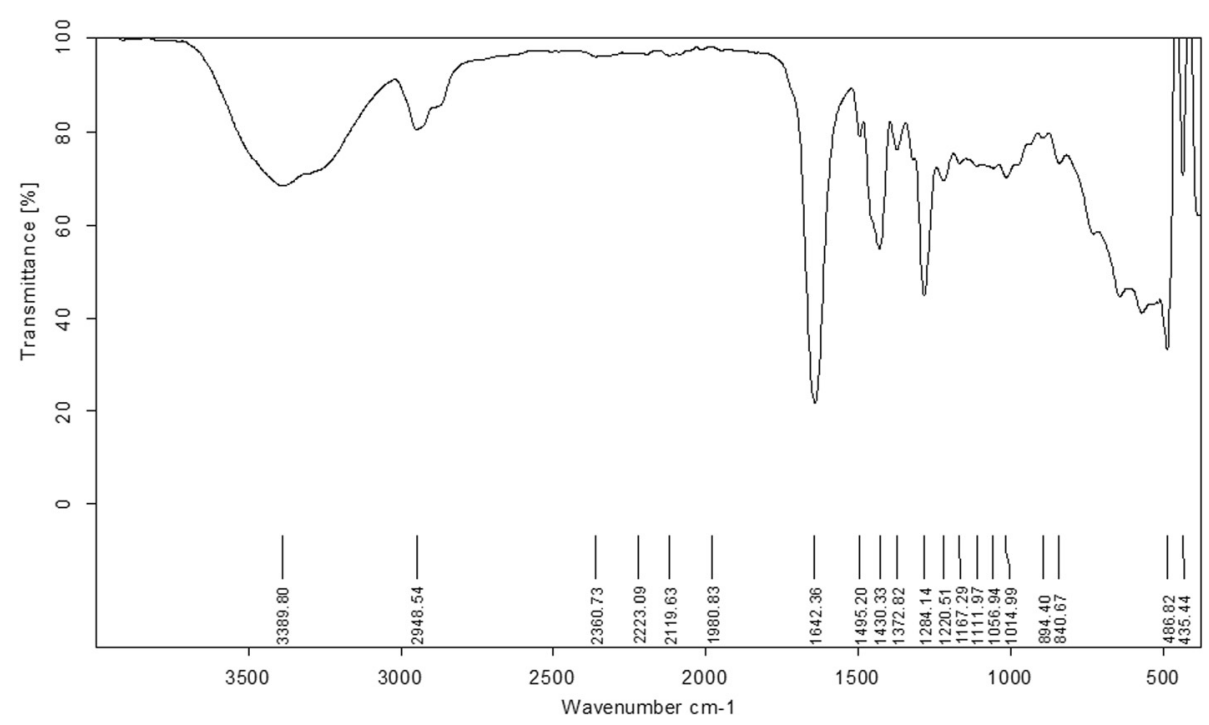

Fig. 2 FTIR spectrum of CA/NCS/PEG (1:2:2) blend membrane 
the membrane formation. Moreover, the $\mathrm{P}-\mathrm{O}$ bond at $1038.87 \mathrm{~cm}^{-1}$ for NCS has undergone a significant shift in the prepared membrane and observed at lower region of $1014.99 \mathrm{~cm}^{-1}$. Thus, the FTIR spectra analysis reflects that the nanoparticles were binded with the CA matrix due to strong interactive forces.

\section{$X R D$}

The X-ray diffraction analysis is a non-destructive analytical technique that gives the information about the crystallographic structure, chemical composition, and physical properties of materials (Subbu et al. 2014). It has been routinely used for crystalline phase identification based on the diffraction peak position and pattern (Jayakrishnan and Ramesan 2016). The crystalline/amorphous ratio of the constituent polymer in a blend plays a vital role in understanding the development of membranes during gelation. Thus, X-ray diffraction patterns of the prepared membrane were measured to investigate the change in the crystalline nature.

Figure 3 shows the X-ray diffractogram of NCS. The percentage of crystallinity was found to be $17 \%$ which may be due to the certain orderliness in its structure which was retained even after the addition of the crosslinker TPP to chitosan. The $2 \theta$ value obtained at $26^{\circ}$ was wider indicating the amorphous nature of the chitosan nanoparticles of size $100 \mathrm{~nm}$. For the chitosan nanoparticles which were in the range of 5-180 nm, the $2 \theta$ value was found to be 20.4357 as reported by Vellingiri et al. (2013).
Figure 4 shows the X-ray diffractogram of CA/NCS/ PEG (1:2:2) blend membrane. The blend showed lesser percentage of crystallinity which is $6 \%$ when compared to NCS whose value was $17 \%$. This revealed that the blend has become more amorphous which may be due to enhanced disruption of orderliness by the addition of nanochitosan and polyethylene glycol in greater amount. It was observed that nanochitosan was amorphous and showed diffraction peaks at $2 \theta$ values $15.19^{\circ}$ and $23^{\circ}$ (Karuppasamy et al. 2012). There was also a significant shift in the $2 \theta$ values to $10.5^{\circ}$ and $29.5^{\circ}$ which were fairly broad. It was also observed that the intensity of the crystalline peaks was decreased and broadened upon the addition of nanochitosan. This disorderliness may be attributed to the formation of intermolecular hydrogen bonding formed between CA, NCS, and PEG, thus favoring the filtration process.

\section{Scanning electron microscopy}

The scanning electron microscope is an extremely useful tool to characterize the surface morphology of the membrane (Zeng et al. 2016) and to investigate the structure of polymeric integrally skinned membrane (Kesting 1985).

The surface morphology of nanochitosan and the blend membrane were observed using SEM and are shown in Figs. 5 and 6. The surface of the membrane helps to identify the significance of membrane in the mechanism of selectivity and permeability. The top layer of membrane is responsible for the permeation whereas the sublayer acts as a mechanical support (Rajesh et al. 2011). The surface

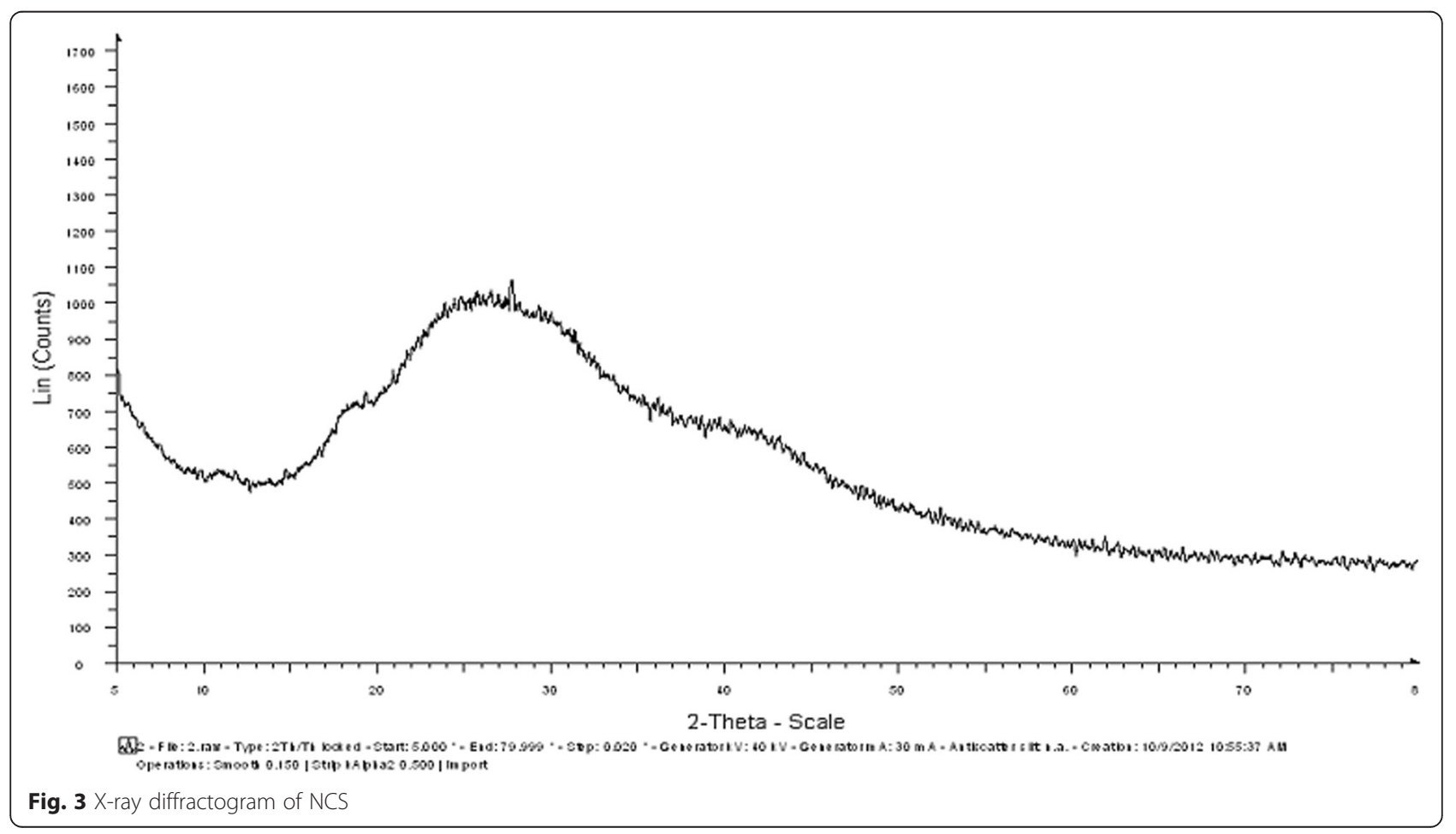




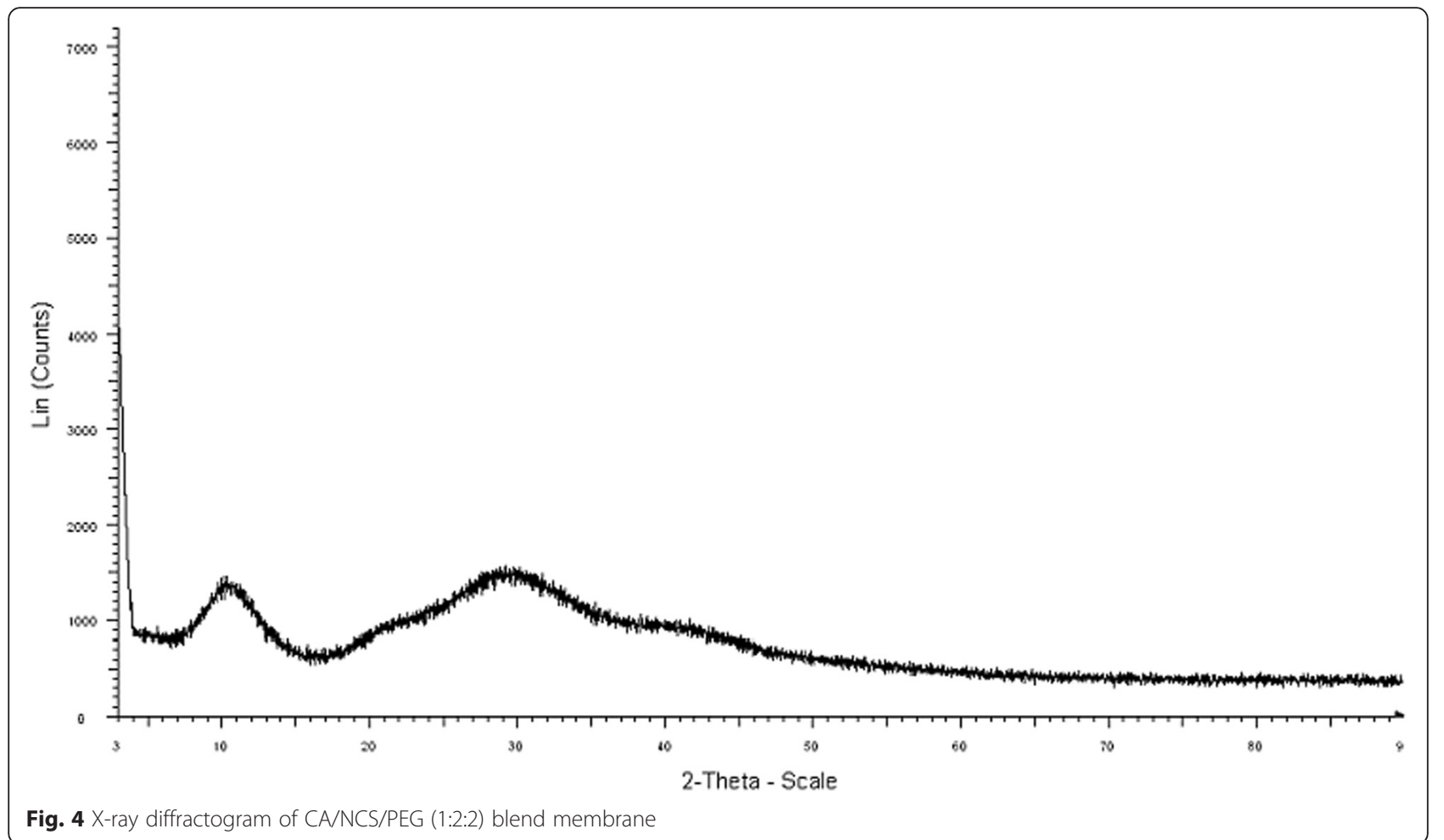

of the prepared membrane clearly shows their asymmetric nature and roughness. The membrane has uniform pores exhibiting more porous structure.

The shape and structure were related to the concentration and composition of additive in the casting solution (Sivakumar et al. 2000). Thus, the prepared membrane was found to be more porous with more PEG content showing small multiple uniform voids when compared with NCS. This is supported by the study done by Saljoughi et al. (2009) that increasing PEG concentration causes formation of greater macrovoids and more porous structures due to

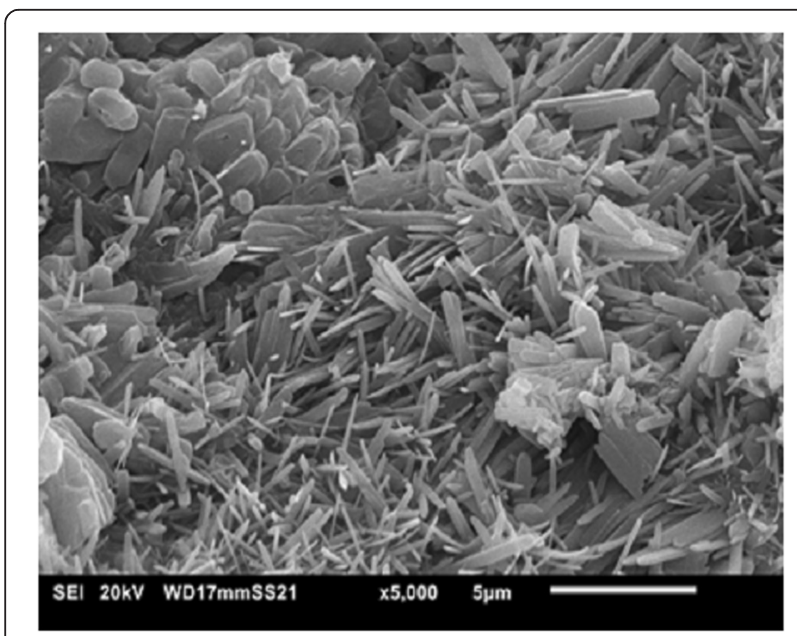

Fig. 5 SEM micrograph of nanochitosan the intensification of thermodynamic instability of the casting solution by PEG. Moreover, the number of pores and pore sizes depends upon the pore forming agent PEG, which leaches out of the membrane in gelation bath during phase separation process (Ananth et al. 2012). However, the pore size of membrane was reduced with increased PEG content in the blend solution (Khulbe et al. 1995) due to the reduced leachability of PEG during gelation in view of strong interactions of PEG with CA and NCS. Hence, the membrane can facilitate the filtration process efficiently.

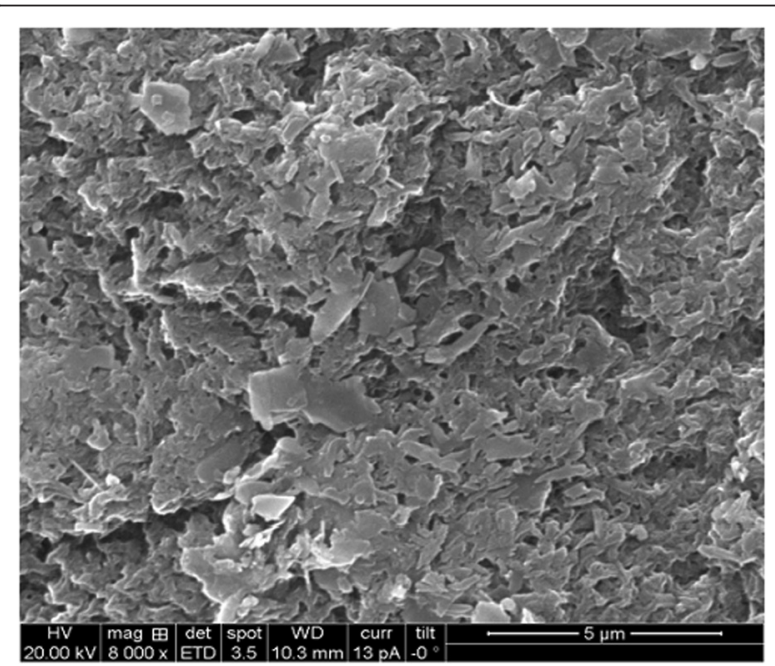

Fig. 6 SEM micrographs of CA/NCS/PEG (1:2:2) blend membrane 


\section{Ultrafiltration characterization of the membrane}

The efficiency of the prepared membrane was found out using various ultrafiltration characterization techniques such as membrane compaction, pure water flux, water content and porosity.

\section{Membrane compaction}

Compaction occurs when membranes are subjected to high pressures. The significance of compaction varies with membrane formulation and operating pressure (Pusch and Mossa 1978). Before using a fresh membrane, it was compacted to make membrane with rigid pore structure and size. When compacted with deionized water for $2 \mathrm{~h}$ at a transmembrane pressure of $240 \mathrm{kPa}$ which is higher than the maximum operating pressure used for the present study, there may be reorganization of the polymeric chains (Maheswari et al. 2013). The limitation of the transmembrane pressure was $<300 \mathrm{kPa}$.

The water flux was calculated from the experimental permeate flow rate measured at every $10 \mathrm{~min}$ interval. During compaction, initially, the pure water flux was found to be high and declines gradually and reaches a steady state after $90 \mathrm{~min}$. This constant value indicates the completion of compaction. This may be due to the fact that the walls of the pores become closer, denser, and uniform resulting in reduction in pore size as well as the flux during compaction (Eren et al. 2015). Furthermore, the polymeric chains reorganize under hydraulic pressure during compaction leading to change in the structure with a lowered volume of porosity.

\section{Pure water flux}

The key requirement of any membrane is pure water flux (PWF), and it was determined for the prepared blend membrane at $100 \mathrm{kPa}$ pressure after completion of compaction. Pure water flux is one of the key components that explain the pore size and pore distribution of the membranes (Shi et al. 2012). It is an essential parameter for the membranes, which is useful for any industrial process. The value of pure water flux of the prepared membrane was found to be $25.32 \mathrm{l} / \mathrm{m}^{2} \mathrm{~h}$.

\section{Water content}

The percentage water content represents the fraction of water molecules occupied in the pores of the membrane. This is considered to be an important parameter for membrane characterization (Tamura et al. 1981), since PWF can be predicted based on these results also. The percent water content was calculated for the prepared membrane, and the value obtained was $24 \%$. This shows that the prepared membrane has become more porous due to the leachability of water-soluble additive, PEG, leading to the formation of more number of pores. This shows the membrane's hydrophilicity since water content of the membrane is related to hydrophilicity of the membrane (Sivakumar et al. 2006).

\section{Porosity}

Porosity, $\varepsilon$, is the void fraction of the membrane. The membrane porosity is related to the pore formation during the process of membrane formation by immersion precipitation (Wienk et al. 1996). A highest percentage of porosity of $83 \%$ was obtained indicating the more porous nature, and it is attributed to the leachability of PEG present in higher concentration.

\section{Remediation of tannery effluent using prepared blend membrane by studying the effect of $\mathrm{pH}$ of the solution, membrane thickness, and applied pressure Effect of $\mathrm{pH}$}

The effect of $\mathrm{pH}$ on the filtration of tannery effluent by the membrane was carried out at room temperature and at three different $\mathrm{pH}$ values, and the results obtained are shown in Figs. 7, 8, and 9.

The $\mathrm{pH}$ of the tannery effluent was changed to acidic, and the filtration process was carried out. It was found that the physicochemical parameters were greatly reduced 


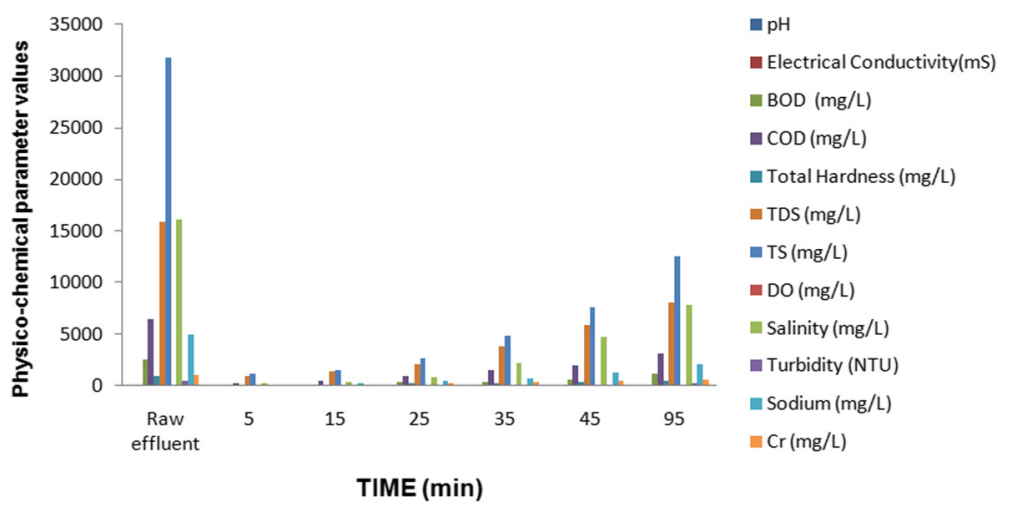

Fig. 8 Physicochemical parameters of the treated effluent at $\mathrm{pH}=7$

after $5 \mathrm{~min}$. With the increase of time, these parameters were found to be increased which may be due to clogging of pores. The percentage removal of chromium at $\mathrm{pH} 5$ was $90.142 \%$ at $5 \mathrm{~min}$ and $39.242 \%$ at $95 \mathrm{~min}$.

The raw effluent itself in the $\mathrm{pH}$ of 7 and the maximum removal was found to take place at this $\mathrm{pH}$. The high concentration of $\mathrm{Cr}$ discharged by leather industries was found to be $1055 \mathrm{mg} / \mathrm{l}$. This was observed to be reduced to $46 \mathrm{mg} / \mathrm{l}$ after $5 \mathrm{~min}$ of filtration and to $586 \mathrm{mg} / \mathrm{l}$ at $95 \mathrm{~min}$. Also, the other physicochemical parameters have found to be significantly reduced. Some even fell within the permissible limit of inland surface waters as given by ISI. The BOD and COD of the effluent were $2556 \mathrm{ml} / \mathrm{l}$ and $6419 \mathrm{mg} / \mathrm{l}$, respectively, which were very high compared to the treated effluent. It was revealed from the results that even after $95 \mathrm{~min}$, the membrane was able to reduce $56.22 \%$ of BOD and $50.97 \%$ of COD. The COD values were found to be hardly decreased as reported by Krishanamoorthi et al. (2009) which may be explained, as COD was mainly soluble consisting in hydrolyzed proteins of low molecular weights, but the effluent has other ionic materials like sodium and chromium.
In the basic medium, the percentage removal of chromium as well as the physicochemical parameters was not as high when compared with that of acidic and neutral medium. The percentage removal of chromium at pH 9 was only $77.915 \%$ at 5 min which is very less when compared at $\mathrm{pH} 5$ and 7 , which are 90.142 and $95.640 \%$, respectively. This may be because the divalent chromium species $\mathrm{CrO}_{4}^{2-}$ which is dominant at high $\mathrm{pH}$ would have formed metal complex with sodium present in the effluent and passed through the membrane (Chen et al. 2008).

Figure 10 indicates the percentage removal of chromium in tannery effluent at $\mathrm{pH} 5, \mathrm{pH} 7$, and $\mathrm{pH} 9$ during various time intervals. The decrease in chromium rejection percentage with time for the studied $\mathrm{pH}$ at 5 , 7 , and 9 may be presumably due to the saturation of the membranes active sites with chromium ions (Habibi et al. 2015). On comparing the values obtained, it was clear that the removal of $\mathrm{Cr}$ was the highest in neutral medium than the acidic medium and was the least at basic medium. As stated by Arthanareeswaran et al. (2007), the rejection increases as the $\mathrm{pH}$ of the chromium solution increases and chosen an optimum $\mathrm{pH}$ of

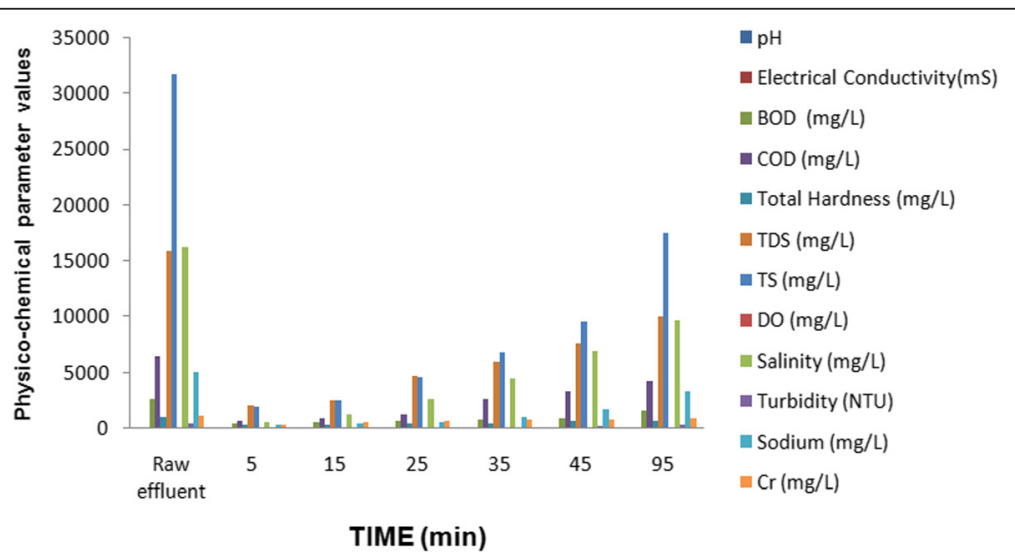

Fig. 9 Physicochemical parameters of the treated effluent at $\mathrm{pH}=9$ 


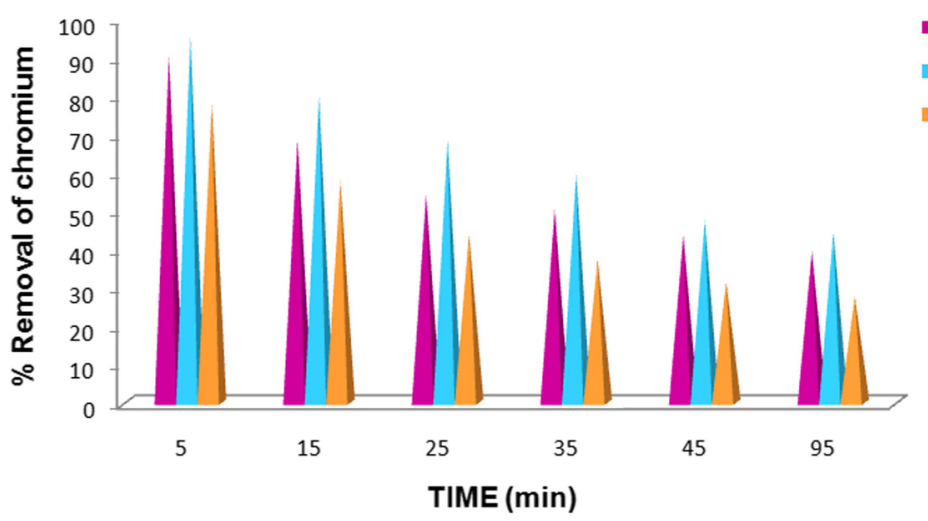

Fig. 10 Effect of time on percentage removal of chromium in tannery effluent at various pH

6 for further rejection studies. The trend of results obtained for tannery effluent was found similar to that of the removal of $\mathrm{Cr}$ using synthetic wastewater which may be attributed to the formation of soluble hydroxides at high $\mathrm{pH}$. Thus, it can be concluded that the membrane can withstand $\mathrm{pH}$ variations from acidic to basic. The maximum efficiencies for different parameters were found at neutral $\mathrm{pH}$ area, and they gradually reduced on both sides of the neutral pH (Chowdhury et al. 2013). Similar observation was made in the current study which may be accounted that the colloid substances in the leather industrial effluents usually carry negative electrical charges, whereas the membrane possesses a lot of positive charge due to the incorporation of chitosan nanoparticles in the polymer membrane matrix which has the capability of adsorbing particles leading to destabilization and thus also led to the assumption that the membrane acts as a adsorptive membrane.

The effect of $\mathrm{pH}$ on chromium rejection plays an important role because the charges of both salt ions and membrane vary with $\mathrm{pH}$ (Verliefde et al. 2008). In a study done by Muthukrishnan and Guha (2008), it was found out that the rejection of chromium greatly increased when
$\mathrm{pH}$ rose from 2 to 7 , as more bivalent $\mathrm{CrO}_{4}^{2-} / \mathrm{Cr}_{2} \mathrm{O}_{7}^{2-}$ ions were generated and the polyamide $\mathrm{NF}$ membrane was more negatively charged at higher $\mathrm{pH}$. Similar findings were given by Yao et al. (2015) in which a quaternary ammonium-based UF membrane (QA membrane) was used to remove $\mathrm{Cr}(\mathrm{VI})$ ions in both acid and neutral $\mathrm{pH}$ more efficiently. Hence, removal of chromium from the membrane separation process is reliant on the $\mathrm{pH}$ of the solution.

\section{Effect of membrane thickness}

The membrane thickness places a crucial role in the removal process. Figure 11 shows the change in various physicochemical parameters at membrane thickness of $0.1 \mathrm{~mm}$.

The EC, BOD, COD, TH, TDS, TS, DO, salinity, turbidity, $\mathrm{Na}$, and $\mathrm{Cr}$ of the raw effluent were drastically high which were found to be reduced to a considerable extent. The EC value of $27.3 \mathrm{mS}$ was observed to be reduced to $7.21 \mathrm{mS}$ during the first $5 \mathrm{~min}$ of filtration which was almost $73 \%$ of reduction. Similarly, the values of BOD, COD, TH, TDS, TS, salinity, turbidity, and $\mathrm{Na}$ which were 2556, 6419, 923, 15900, 31740,

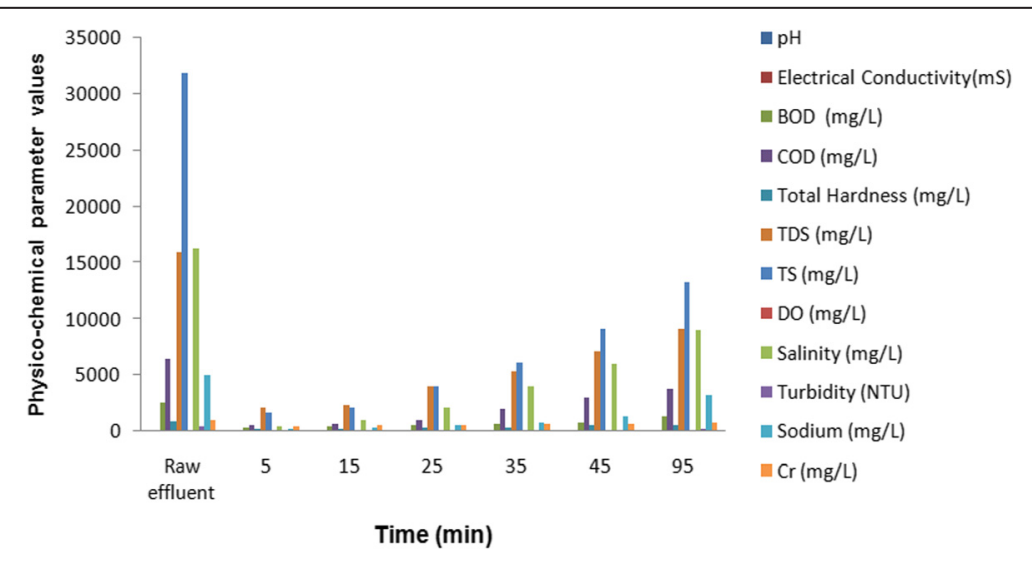

Fig. 11 Physicochemical parameters of the treated effluent at thickness $=0.1 \mathrm{~mm}$ 
16200,453 and $5000 \mathrm{mg} / \mathrm{l}$ has been reduced to 312,513 , $223,2095,1654,415,42$ and $218 \mathrm{mg} / \mathrm{l}$, respectively. The percentage of chromium removal was $56.967 \%$ at $5 \mathrm{~min}$ and even at $95 \mathrm{~min}$; the membrane has the efficiency to remove about $30.237 \%$ of chromium.

Figure 12 shows the change in the physicochemical parameters when used $0.2 \mathrm{~mm}$ of the thickness of membrane. It was evident that there was a vital increase in the removal efficiency of the membrane when its thickness was increased from 0.1 to $0.2 \mathrm{~mm}$. The values of BOD, COD, TH, TDS, TS, salinity, turbidity, and Na which were $312,513,223,2095,1654,415,42$ and $218 \mathrm{mg} / \mathrm{l}$, respectively, when used $0.1 \mathrm{~mm}$ of membrane were found to be still reduced to $113,237,93,944,1162$, 210, 22 and $112 \mathrm{mg} / \mathrm{l}$, respectively. This enhancement in the removal efficiency may be attributed to thin skin layer and porous sublayer of the asymmetric membrane containing more number of voids. The EC was also retarded from 7.21 to $3.22 \mathrm{mS}$. In addition, the DO was found to be increased from 0.2 to $4.2 \mathrm{mg} / \mathrm{l}$ which favors the life of the aquatic ecosystem since the accepted limit given by ISI was $4-6 \mathrm{mg} / \mathrm{l}$.

Figure 13 shows the effect of time on the percentage removal of chromium using 0.1 and $0.2 \mathrm{~mm}$ thickness of the membrane. It can be seen that the percentage removal of chromium with $0.1 \mathrm{~mm}$ thickness was $56.967 \%$ which was less when compared with $0.2 \mathrm{~mm}$ thickness which gives removal percentage of 95.640. With the increase of time, the removal efficiency was retarded due to pore blocking. This was evidenced by a study conducted by Jyothi et al. (2014) in which the percentage rejection of chromium decreases as time increases. The same trend was observed till the $95 \mathrm{~min}$, i.e., $30.237 \%$ for $0.1 \mathrm{~mm}$ and $44.455 \%$ for $0.2 \mathrm{~mm}$ thickness. It was obvious that as the membrane thickness increased, the percentage removal of chromium was also increased. An increase in membrane thickness correlates to a decrease in permeation flux and better retention of solute. This could be attributed that membranes had larger pores with increasing thickness (Abdelrasoul et al. 2015). Due to practical difficulties, using of $0.3 \mathrm{~mm}$ thickness has been avoided. Moreover, better removal of $\mathrm{Cr}$ and other physicochemical parameters has been obtained using $0.2 \mathrm{~mm}$ membrane thickness itself.

From the results, it was clear that the membrane thickness was a function of permeation characteristics and it was proved by Gotoh et al. (1993) that the flux for aqueous solution of dextran sodium sulfate decreased with an increase in membrane thickness, while the rejection for dextran sodium sulfate increased slightly. In another study by Barakat (2008), the metal ions rejection efficiency values were increased with $\mathrm{pH}$ increase, reaching maxima values at $\mathrm{pH}=7$, i.e., $97.6,99.1$, and $99.5 \%$, for $\mathrm{Cu}(\mathrm{II}), \mathrm{Ni}(\mathrm{II})$, and $\mathrm{Cr}(\mathrm{III})$ ions, respectively. Moreover, the percentage of TDS retention was only $86.8 \%$ for $0.1 \mathrm{~mm}$ thickness whereas it was $94 \%$ for $0.2 \mathrm{~mm}$ thickness which showed a closer value obtained by Kowalik-Klimczak and Gierycz (2014) which is $99.6 \%$ of retention by UF.

\section{Effect of applied pressure}

Ultrafiltration process itself is a pressure-driven process except that it needs only minimum pressure for the filtration process to take place. In the porous UF membrane, the transport of solvent is directly proportional to the applied pressure (Trivunac and Stevanovic 2006). Two different pressures namely 50 and $100 \mathrm{kPa}$ have been employed in this study and analyzed the changes that have taken place before and after filtration.

Figure 14 shows the effect of pressure on the removal of various physicochemical parameters at $50 \mathrm{kPa}$. The EC was found to be reduced from 27.3 to $7.22,8.42$, 9.31, 9.88, 10.74 and $13.5 \mathrm{mS}$ at 5, 15, 25, 35, 45 and 95 min, respectively. The BOD and COD were found to be 2556 and $6419 \mathrm{mg} / \mathrm{l}$ which were reduced to 315,411 , 599, 628, 781 and $1301 \mathrm{mg} / \mathrm{l}$ for BOD and 525, 731,

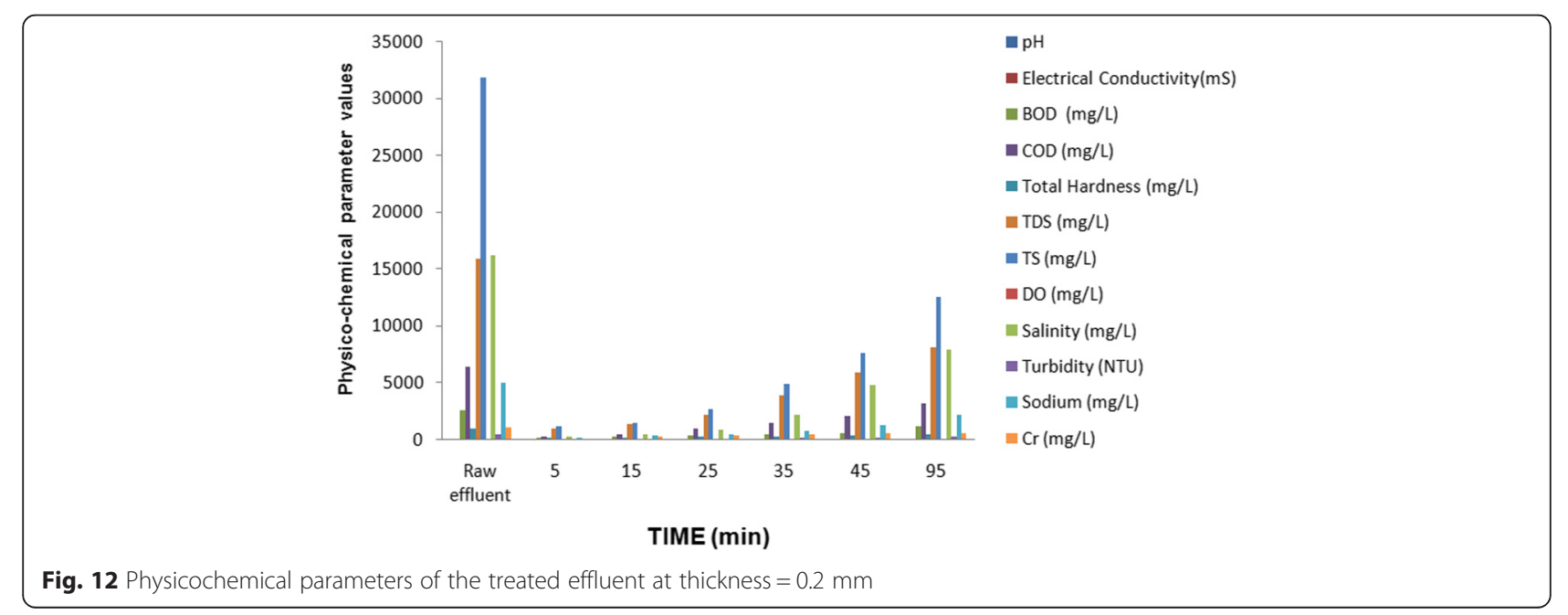




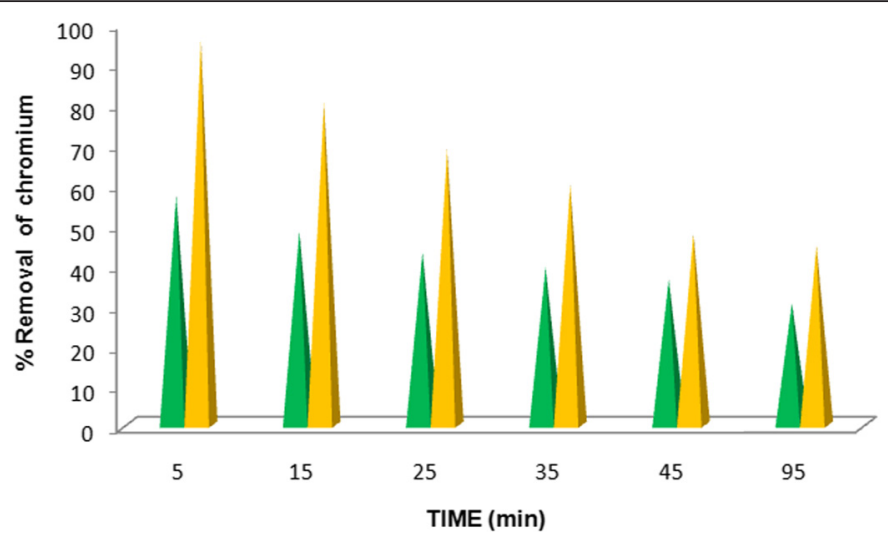

$0.1 \mathrm{~mm}$

$0.2 \mathrm{~mm}$

1066, 2216, 3022 and $3984 \mathrm{mg} / \mathrm{l}$ for COD at 5, 15, 25, 35, 45 and $95 \mathrm{~min}$, respectively. Other parameters were also found to be reduced to a considerable amount. The heavy metal chromium was also reduced to a greater extent namely from 1055 to $333,389,473,593,684$ and $749 \mathrm{mg} / \mathrm{l}$.

Figure 15 shows the effect of pressure on the removal of various physicochemical parameters at $100 \mathrm{kPa}$. All the parameters were found to be greatly enhanced when the pressure was increased from 50 to $100 \mathrm{kPa}$. As can be seen, the EC values which were 7.22, 8.42, 9.31, 9.88, 10.74 and $13.5 \mathrm{mS}$ using $50 \mathrm{kPa}$ at $5,15,25,35,45$ and 95 min were found to be reduced to $3.22,5.41,6.21$, $8.16,10.2$ and $13.1 \mathrm{mS}$ at $100 \mathrm{kPa}$, respectively. The BOD values at $5,15,25,35,45$ and $95 \mathrm{~min}$ at $50 \mathrm{kPa}$ were $315,411,599,628,781$ and $1301 \mathrm{mg} / \mathrm{l}$, respectively, which were further decreased to 113, 159, 295, 364, 545 and $1119 \mathrm{mg} / \mathrm{l}$, respectively, at $100 \mathrm{kPa}$. In the same way, the COD values were also retarded. TH, TDS, TS, salinity, turbidity, and sodium values were all decreased, i.e., more percentage removal was observed when the pressure has been increased from 50 to $100 \mathrm{kPa}$. In turn, the DO values have been increased for the survival of aquatic organisms.

Figure 16 shows the percentage removal of chromium at pressures 50 and $100 \mathrm{kPa}$ during various time intervals. It was very much evident that the percentage removal of chromium which was only $68.436 \%$ at $50 \mathrm{kPa}$ was improved at $100 \mathrm{kPa}$ whose removal percentage was found to be $95.640 \%$. Similar trend was observed as the time was increased. But there is a reduction in percentage removal of chromium with time which may be due to the applied pressure that the pollutants adsorbed in the pore of the membrane move slowly to the permeate during filtration. Thus, the permeate chromate concentration increased with the passage of time (Bade et al. 2008). Thus, the membrane was capable of removing $29.005 \%$ of chromium at $50 \mathrm{kPa}$ and $44.455 \%$ of chromium at $100 \mathrm{kPa}$ at $95 \mathrm{~min}$. Hence, with an increase of the applied pressure, better rejection of the metal ions

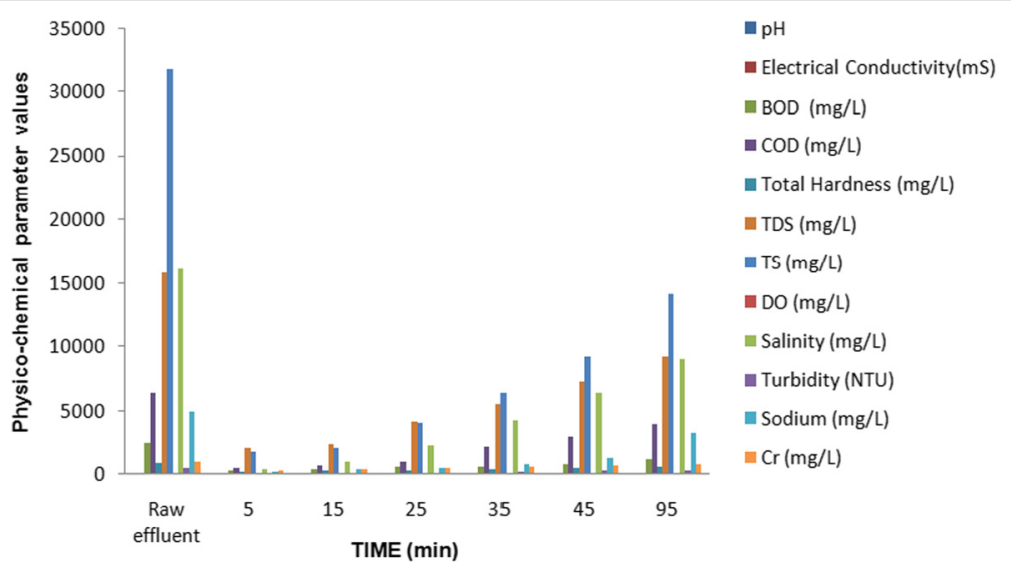

Fig. 14 Physicochemical parameters of the treated effluent at pressure $=50 \mathrm{kPa}$ 


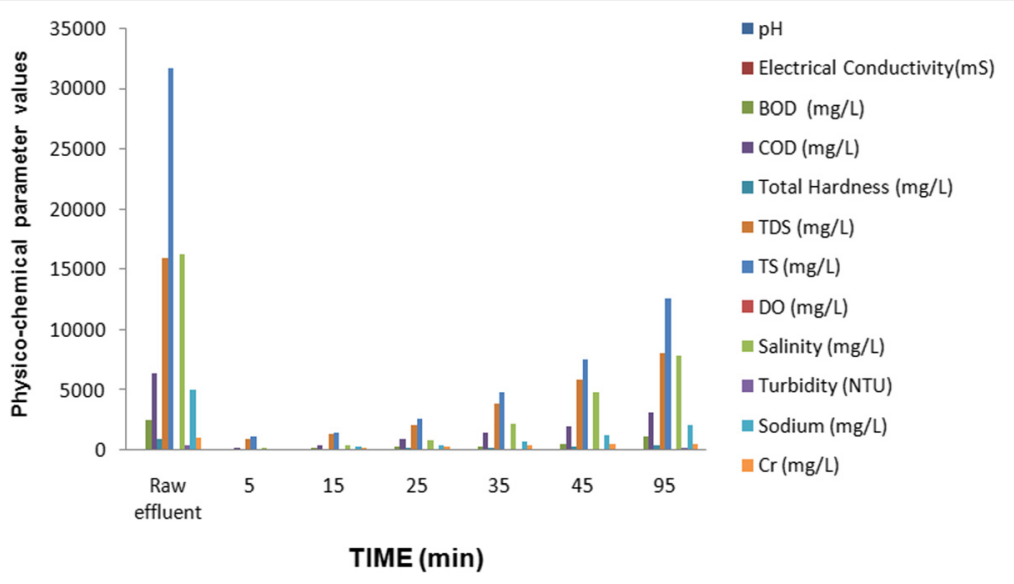

Fig. 15 Physicochemical parameters of the treated effluent at pressure $=100 \mathrm{kPa}$

was obtained. Since high percentage chromium removal of $95.640 \%$ was obtained at $100 \mathrm{kPa}$, further increase in applied pressure was not carried out in this study.

Also, in a study on the effect of applied pressure (0.4$1 \mathrm{MPa}$ ) on percentage solute rejection of chromium and copper ions by Boricha and Murthy (2010), it was found that the rejection increases with increase in feed pressure from 0.4 to $1 \mathrm{MPa}$ for both the ions and the highest rejection was found to be 83.40 and $72.60 \%$ for chromium and copper ions, respectively, at $1 \mathrm{MPa}$. In addition, the increase in the applied pressure increases the surfactant concentration polarization layer near the membrane surface on which the metal ions gets adsorbed (Kamble and Marathe 2005). Thus, when the charged species flows across a membrane, an unbalanced distribution of the electrical charges at the upstream and downstream interfaces of the membrane takes place. This consequently generates streaming potential, and as stated by Azoug et al. (1997), an increase of the transmembrane pressure may lead to a better rejection of the metal ions.

\section{Conclusions}

In this study, nanochitosan was prepared successfully with particle size of $100 \mathrm{~nm}$. The membrane was prepared using phase inversion method and characterized using FTIR, XRD and SEM. Ultrafiltration characterization was done by membrane compaction, pure water flux, water content and porosity. FTIR result revealed that the polymers used have been blended well. XRD showed that the membrane is amorphous in nature and SEM exhibited rough surface and large number of pores. The results showed that the membrane obtained a pure water flux of $25.32 \mathrm{l} / \mathrm{m}^{2} \mathrm{~h}$. The water content was found to be $24 \%$, and a high porosity of $83 \%$ was obtained which showed the membrane's high hydrophilicity and more porous nature. So the prepared membrane was used for the filtration of tannery effluent collected from Ranipet Industrial area. It can be concluded from this study that the membrane CA/NCS/PEG in 1:2:2 ratio was found to be suitable for reducing the physicochemical parameters such as EC, BOD, COD, TH, TDS, TS, salinity, turbidity and

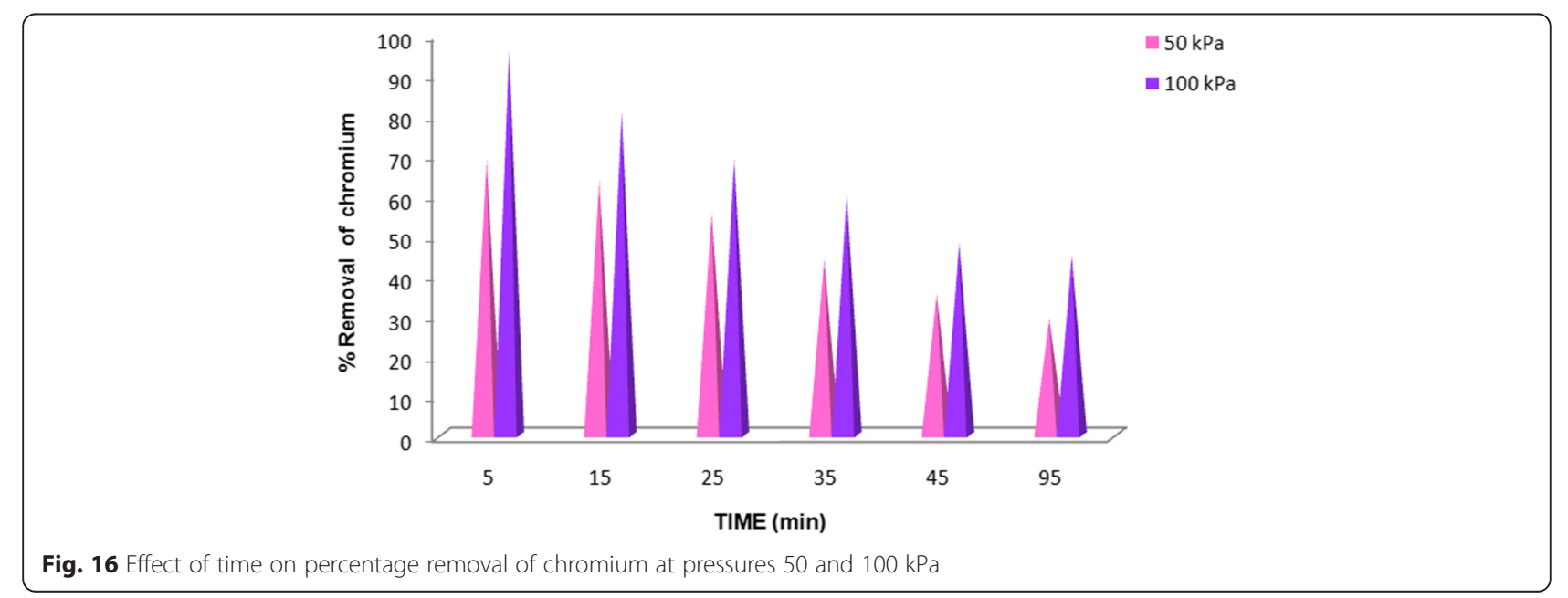


sodium as well as the heavy metal chromium from tannery effluent in an effective and efficient way. The effect of $\mathrm{pH}$, membrane thickness and the applied pressure was analyzed and found that maximum removal has taken place when the effluent was in neutral condition, at $0.2 \mathrm{~mm}$ membrane thickness and pressure $100 \mathrm{kPa}$. This membrane ratio could further be implemented at industrial level for the utmost benefit of mankind.

\section{Competing interests}

None of the authors have any competing interests including direct or indirect financial relations with any of the trademarks and company mentioned in this paper except that University Grants Commission (UGC), New Delhi, India, has funded this project.

\section{Authors' contributions}

PNS and PAV contributed to the conception and design of the study. PAV carried out the experiments, analyzed the data, and drafted the manuscript. PNS supervised the works. Both authors read and approved the final manuscript.

\section{Acknowledgements}

One of the authors Ms. P. AngelinVinodhini acknowledges with gratitude the financial support (JRF) given by University Grants Commission (UGC), New Delhi. P.N.Sudha acknowledges University Grants Commission (UGC), New Delhi, India, for funding the project.

Received: 17 December 2015 Accepted: 14 March 2016 Published online: 01 April 2016

\section{References}

Abdelrasoul, A, Doan, H, Lohi, A, \& Cheng, C-H (2015). Morphology control of polysulfone membranes in filtration processes: a critical review. Chem Bio Eng Rev, 2(1), 22-43.

Ananth, A, Arthanareeswaran, G, \& Wang, H (2012). The influence of tetraethylorthosilicate and polyethyleneimine on the performance of polyethersulfone membranes. Desalination, 287, 61-70.

APHA. (1993). Standard methods for the examination of water and wastewaters (p. 874). NW, Washington DC: American Public Health Association.

Arthanareeswaran, G, Thanikaivelan, P, Srinivasan, K, Mohan, D, \& Rajendran, M (2004). Synthesis, characterization and thermal studies on cellulose acetate membranes with additive. European Polymer Journal, 40, 2153-2159.

Arthanareeswaran, G, Thanikaivelan, P, Raguime, J A, Raajenthiren, M, \& Mohan, D (2007). Metal ion separation and protein removal from aqueous solutions using modified cellulose acetate membranes: role of polymeric additives. Separation and Purification Technology, 55, 8-15.

Azoug, C, Sadaoui, Z, Charbit, F, \& Charbit, G (1997). Removal of cadmium from wastewater by enhanced ultrafiltration using surfactants. The Canadian Journal of Chemical Engineering, 75(4), 743-750.

Bade, R, Lee, S H, Jo, S, Lee, H-S, \& Lee, S-e (2008). Micellar enhanced ultrafiltration (MEUF) and activated carbon fibre (ACF) hybrid processes for chromate removal from wastewater. Desalination, 229, 264-278.

Barakat, M A (2008). Removal of Cu(II), Ni(II), and $\mathrm{Cr}(\mathrm{III})$ ions from wastewater using complexation-ultrafiltration technique. Journal of Environmental Science and Technology, 1(3), 151-156.

Barbooti, M M (2015). Simultaneous removal of chromium and lead from water by sorption on Iraqi Montmorillonite. Journal of Environmental Protection, $6,237-249$.

Boonlertniruni, S, Boobraung, C, \& Suvanasara, R (2008). Application of chitosan in rice production. Journal of Metals Materials and Minerals, 18, 47-52.

Boricha, A G, \& Murthy, Z V P (2010). Preparation of N, O-carboxymethyl chitosan/cellulose acetate blend nanofiltration membrane and testing its performance in treating industrial wastewater. Chemical Engineering Journal, 157, 393-400.

Chen, S-S, Hsu, B-C, Ko, C-H, \& Chuang, P-C (2008). Recovery of chromate from spent plating solutions by two-stage nanofiltration processes. Desalination, 229, 147-155.

Chowdhury, M, Mostafa, M G, Biswas, T K, \& Saha, A K (2013). Treatment of leather industrial effluents by filtration and coagulation processes. Water Resources and Industry, 3, 11-22.
Crini, G (2005). Recent developments in polysaccharide-based materials used as adsorbents in wastewater treatment. Progress in Polymer Science, 30, 38-70.

De Lima, R, Feitosa, L, Santo Pereira, A E, De Moura, M R, Fauze Ahmad Aouada, F A, Mattoso, L H C, Fraceto, L F (2010). Evaluation of the genotoxicity of chitosan nanoparticles for use in food packaging films. Journal of Food Science, 75, 89-96.

Duruibe, J O, Ogwuegbu, M O C, \& Egwurugwu, J. N. (2007). Heavy metal pollution and human biotoxic effects. International Journal of Physical Sciences, 2(5), 112-118.

El Hadrami, A, Adam, L R, El Hadrami, I, \& Daayf, F (2010). Chitosan in plant protection. Marine Drugs, 8, 968-987.

Eren, E, Sarihan, A, Eren, B, Gumus, H, \& Kocak, F O (2015). Preparation, characterization and performance enhancement of polysulfone ultrafiltration membrane using PBI as hydrophilic modifier. Journal of Membrane Science, 475, 1-8.

Gökşen, Ç (2005). Development of a membrane based treatment scheme for water recovery from textile effluents (M.Sc. Thesis). Ankara: Middle East Technical University.

Gorey, C, \& Escobar, I C (2011). N-isopropylacrylamide (NIPAAM) modified cellulose acetate ultrafiltration membranes. Journal of Membrane Science, 383, 272-279.

Gotoh, M, Tamiya, E, \& Karube, I (1993). Preparation and performance of poly (vinyl butyral) membrane for ultrafiltration. Journal of Applied Polymer Science, 48, 67-73.

Habibi, S, Nematollahzadeh, A, \& Mousavi, S A (2015). Nano-scale modification of polysulfone membrane matrix and the surface for the separation of chromium ions from water. Chemical Engineering Journal, 267, 306-316.

Ham-Pichavant, F, Sebe, G, Pardon, P, \& Coma, V (2005). Fat resistance properties of chitosan-based paper packaging for food applications. Carbohydrate Polymers, 61, 259-265.

Idris, A, \& Yet, L K (2006). The effect of different molecular weight PEG additives on cellulose acetate asymmetric dialysis membrane performance. Journal of Membrane Science, 280, 920-927.

Jayakrishnan, P, \& Ramesan, M T (2016). Synthesis, characterization and properties of poly (vinyl alcohol)/chemically modified and unmodified pumice composites. Journal of Chemical and Pharmaceutical Sciences, 1, 97-104.

Jyothi, M S, Nayak, V, Padaki, M, Geetha Balakrishna, R, \& Ismail, A F (2014). The effect of UV irradiation on $\mathrm{PSf} / \mathrm{TiO} \mathrm{O}_{2}$ mixed matrix membrane for chromium rejection. Desalination, 354, 189-199.

Kamble, S B, \& Marathe, K V (2005). Micellar-enhanced ultrafiltration of chromate $[\mathrm{Cr}(\mathrm{VI})]$ ion from aqueous streams by using cationic surfactant. Indian Journal of Chemical Technology, 12, 393-400.

Karuppasamy, K, Thanikaikarasan, S, Antony, R, Balakumar, S, \& Shajan, X S (2012). Effect of nanochitosan on electrochemical, interfacial and thermal properties of composite solid polymer electrolytes. Ionics, 18(8), 737-745.

Kato, Y, Onishi, H, \& Machida, Y (2003). Application of chitin and chitosan derivatives in the pharmaceutical field. Current Pharmaceutical Biotechnology, 4, 303-309.

Kesting, R E (1985). Synthetic polymeric membranes: a structural perspective. New York: Wiley.

Khulbe, K C, Gagne, S, Mohammadi, A T, \& Lamarche, A M (1995). Investigation of polymer morphology of integral asymmetric membranes by ESR and raman spectroscopy and its comparison with homogeneous films. Journal of Membrane Science, 98, 201.

Kowalik-Klimczak, A, \& Gierycz, P (2014). Application of pressure membrane processes for the minimization of the noxiousness of chromium tannery wastewater. Problemy Eksploatacji - Maintenance Problems, 1, 71-79.

Krishanamoorthi, S, Sivakumar, V, Saravanan, K., \& Sriram Prabhu, T V (2009). Treatment and reuse of tannery waste water by embedded system. Modern Applied Science, 3(1), 129-134.

Kumar, M N V R, Muzzarelli, R A A, Muzzareli, C, Sashiwa, H, \& Domb, A J (2004). Chitosan chemistry and pharmaceutical perspectives. Chemical Reviews, 104, 6017-6084.

Kuttowy, O, \& Sourirajan, S (1975). Cellulose acetate ultrafiltration membranes. Journal of Applied Polymer Science, 19, 1449-1460.

Li, J F, Xu, Z L, Yang, H, Yu, L Y, \& Liu, M (2009). Effect of $\mathrm{TiO}_{2}$ nanoparticles on the surface morphology and performance of microporous PES membrane. Applied Surface Science, 255, 4725-4732.

Loeb, S, \& Sourirajan, S (1963). Sea water demineralization by means of an osmotic membrane. In Advances in Chemistry (pp. 117-132). Washington, DC: ACS publications.

Maheswari, P, Prasannadevi, D, \& Mohan, D (2013). Preparation and performance of silver nanoparticle incorporated polyetherethersulfone nanofiltration membranes. High Performance Polymers, 25(2), 174-187. 
Malik, D, Singh, S, Thakur, J, Singh, R K, Kaur, A, \& Nijhawan, S (2014). Heavy metal pollution of the Yamuna river: an introspection. International Journal of Current Microbiology and Applied Science, 3(10), 856-863.

Mohammadpour Dounighi, N, Behfar, A, Ezabadi, A, Zolfagharian, H, \& Heydari, M (2010). Preparation of chitosan nanoparticles containing Naja naja oxiana snake venom. Nanomedicine: Nanotechnology, Biology, and Medicine, 6, 137-143.

Moosa, A A, Ridha, A M, \& Abdullha, I N (2015). Chromium ions removal from wastewater using activated Iraqi Bentonite. International Journal of Innovative Research in Science, Engineering and Technology, 4(2), 15-25.

Muthukrishnan, M, \& Guha, B K (2008). Effect of pH on rejection of hexavalent chromium by nanofiltration. Desalination, 219, 171-178.

Nara, S, \& Komiya, T (1983). Studies on the relationship between water-saturated state and crystallinity by the diffraction method for moistened potato starch. Starch-starke, 35, 407-410.

Nath, K (2008). Membrane separation processes. New Delhi: PHI Learning Pvt. Ltd.

$\mathrm{Ng}, \mathrm{L}$ T, \& Swami, S (2005). IPNs based on chitosan with NVP and NVP/ HEMAsynthesised through photoinitiator-free photopolymerisation technique forbiomedical applications. Carbohydrate Polymer, 60, 523-528.

Northcott, K A, Snape, I, Scales, P J, \& Stevens, G W (2005). Dewatering behaviour of water treatment sludges associated with contaminated site remediation in Antarctica. Chemical Engineering Science, 60(24), 6835-6843.

Osada, V, \& Nakagawa, I (1992). Membrane science and technology. New York: Marcel Dekker.

Pang, M, Liu, B, Kano, N, \& Imaizumi, H (2015). Adsorption of chromium (VI) onto activated carbon modified with $\mathrm{KMnO}_{4}$. Journal of Chemistry and Chemical Engineering, 9, 280-287.

Pusch, W. \& Mossa, G (1978). Influence of pressure and/or pressure differential on membrane permeability. Desalination, 24, 39-53.

Qu, P, Tang, H, Gao, Y, Zhang, L-p, \& Wang, S (2010). Polyethersulfone composite membrane blended with cellulose fibrils. BioResources, 5(4), 2323-2336.

Rajesh, S, Maheswari, P, Senthilkumar, S, Jayalakshmi, A, \& Mohan, D (2011). Preparation and characterisation of poly (amide-imide) incorporated cellulose acetate membranes for polymer enhanced ultrafiltration of metal ions. Chemical Engineering Journal, 171, 33-44.

Rinoudo, M (2006). Chitin and chitosan: properties and applications. Progress in Polymer Science, 31, 603-632.

Rowe, R C, Sheskey, P J, \& Weller, P J (2003). Handbook of pharmaceutical excipients (4th ed.). Washington, DC: American Pharmaceutical Association.

Saljoughi, E.Sadrzadeh, M, \& Mohammadi, T (2009). Effect of preparation variables on morphology and pure water permeation flux through asymmetric cellulose acetate membranes. Journal of Membrane Science, 326, 627-634.

Shi, F, Ma, Y, Ma, J, Wang, P, \& Sun, W (2012). Preparation and characterization of $\mathrm{PVDF} / \mathrm{TiO}_{2}$ hybrid membranes with different dosage of nano- $\mathrm{TiO}_{2}$. Journal of Membrane Science, 389, 522-531.

Sivakami, M S, Gomathi, T, Venkatesan, J, Jeong, H-S, Kim, S-K, \& Sudha, P N (2013). Preparation and characterization of nano chitosan for treatment wastewaters. International Journal of Biological Macromolecules, 57, 204-212.

Sivakumar, M, Malaisamy, R, Sajitha, C J, Mohan, D, Mohan, V, \& Rangarajan, R (2000). Preparation and performance of cellulose acetate-polyurethane blend membranes and their applications-II. Journal of Membrane Science, $169,215-228$

Sivakumar, M, Mohan, D R, \& Rangarajan, R (2006). Studies on cellulose acetatepolysulfone ultrafiltration membranes II. Effect of additive concentration. Journal of Membrane Science, 268, 208-219.

Subbu, C, Chithra Mathew, M, Kesavan, K, \& Rajendran, S (2014). Electrochemical, structural and optical studies on poly(vinylidene chloride-co-acrylonitrile) based polymer blend membranes. International Journal of Electrochemical Science, 9, 4944-4958.

Sudha, P N (2010). Chitin/chitosan and derivatives for wastewater treatment. In S-K Kim (Ed.), Chitin, Chitosan, Oligosaccharides and Their Derivatives (pp. 561-585). Boca Raton: CRC Press.

Suh, J K F, \& Matthew, H W T (2000). Application of chitosan-based polysaccharide biomaterilas in cartilage tissue engineering: a review. Biomaterials, 21, 2589-2598.

Sun, L, Du, Y, Yang, J H., Shi, X W, Li, J, Wang, X H, Kennedy, JF (2006). Conversion of crystal structure of the chitin to facilitate preparation of a 6-carboxychitin with moisture absorption-retention abilities. Carbohydrate Polymers, 66(2), 168-175.

Tamura, M, Uragami, T, \& Sugihara, M (1981). Studies on synthesis and permeabilities of special polymer membranes, CA30. Ultrafiltration and dialysis characteristics of cellulose nitrate poly (vinylpyrrolidone) polymer blend membranes. Polymer, 22, 829-835.
Trivedy, R K, \& Goel, P K (1986). Chemical and biological methods for water pollution studies (pp. 43-45). Karad: Environ. Publications.

Trivunac, K, \& Stevanovic, S (2006). Removal of heavy metal ions from water bycomplexation-assisted ultrafiltration. Chemosphere, 64, 486-491.

Tucci, M G, \& Rocotti, G (2003). Chitosan and gelatin as engineered dressing for wound repair. Journal of Bioactive and Compatible Polymer, 16, 145-157.

Vellingiri, K, Ramachandran, T, \& Senthilkumar, M (2013). Eco-friendly application of nano chitosan in antimicrobial coatings in the textile industry. Nanoscience and Nanotechnology, 3(4), 75-89.

Velu, S, Muruganandam, L, \& Arthanareeswaran, G (2011). Effect of solvents on performance of polyethersulfone ultrafiltraion membranes for separation of metal ions. International Journal of Chemical and Analytical Science, 2, 82-86.

Verliefde, A R D, Cornelissen, E R, Heijman, S G J, Verberk, J Q J C, Amy, G L, Van der Bruggen, B, van Dijk, J C (2008). The role of electrostatic interactions on the rejection of organic solutes in aqueous solutions with nanofiltration. Journal of Membrane Science, 322, 52-66.

Vijayalakshmi, K, Gomathi, T, \& Sudha, P N (2014). Preparation and characterization of nanochitosan/sodium alginate/microcrystalline cellulose beads. Der Pharmacia Lettre, 6(4), 65-77.

Vimal, S, Abdul Majeed, S, Taju, G, Nambi, K S N, Sundar Raj, N, Madan, N, Farook, M A, Rajkumar, T, Gopinath, D, Sahul Hameed, A S (2013). Chitosan tripolyphosphate (CS/TPP) nanoparticles: preparation, characterization and application for gene delivery in shrimp. Acta Tropica, 128, 486-493.

Wienk, I M, Boom, R M, Beerlage, M A M, Bulte, A M W, Smolders, C A, \& Strathmann, $H$ (1996). Recent advances in the formation of phase inversion membranes made from amorphous or semi-crystalline polymers. Journal of Membrane Science, 113, 361-371.

Witte, P V, Dijkstra, P J, Vanden Berg, J W A, \& Feijen, J (1996). Phase separation process in polymer solution in relation to membrane formation. Journal of Membrane Science, 117, 1-31.

Yao, Z, Shiyuan, D, Zhang, Y, Zhu, B, Zhu, L, \& John, A E (2015). Positively charged membrane for removing low concentration $\mathrm{Cr}(\mathrm{VI})$ in ultrafiltration process. Journal of Water Process Engineering, 8, 99-107.

Yu, J H. Du, Y M, \& Zheng, H (1999). Blend films of chitosan-gelation. Journal Wuhan University, 45, 440-444.

Zeng, J, Ye, H, \& Hu, Z J (2009). Application of the hybrid complexationultrafiltration process for metal ion removal from aqueous solutions. Journal of Hazardous Materials, 161(2-3), 1491-1498.

Zeng, G, Lian, G, Zhang, Y, Lu, G, Zhou, Y, Qiu, J, van der Bruggencd, B, Shen, J (2016). Potential applications of abandoned aromatic polyamide reverse osmosis membrane by hypochlorite degradation. RSC Advances, 6, 1226312271.

\section{Submit your manuscript to a SpringerOpen ${ }^{\mathcal{O}}$ journal and benefit from:}

- Convenient online submission

- Rigorous peer review

- Immediate publication on acceptance

- Open access: articles freely available online

- High visibility within the field

- Retaining the copyright to your article

Submit your next manuscript at springeropen.com 